\title{
Physical Health Decision-Making Autonomy Preferences for Adults With Severe Mental Illness In Integrated Care
}

\author{
Jennifer Wright-Berryman, Ph.D. \\ Indiana University - Purdue University (IUPUI) \\ Indianapolis, Indiana
}

\section{Statement of Research Problem}

Mental health disorders account for four of the ten leading causes of disability in the U.S. (NIMH, 2001), and severe mental illnesses such as schizophrenia, bipolar disorder, and major depression are found in approximately 5\% of the U.S. population (McGrath, Saha, Chant, \& Welham, 2008). People with severe mental illnesses (SMI) often have comorbid physical conditions that contribute to morbidity and mortality rates that are higher than the general population (Jones et al., 2004). According to a recent meta-analysis (Mitchell et al., 2013), 50\% of people with schizophrenia are overweight, $20 \%$ have high blood sugar, and $40 \%$ have abnormal lipid levels. Overall, people with SMI died approximately 25 years earlier than the general population, and approximately 10 years earlier than those with non-severe mental illnesses, such as milder forms of depression and anxiety (Lutterman, 2003).

\section{Decision-Making Autonomy Preferences}

One patient behavior that has gone largely unstudied is decision-making autonomy preferences, in other words, how much control a person desires to have over their physical healthcare decisions. This could be an important behavior to study, as a decision to follow a treatment recommendation, such as filling or taking a prescription medication, is directly linked to treatment outcomes (Bosworth, Oddone, \& Weinberger, 2008). A review by Street, Elwyn, and Epstein (2012) of the general population suggests that a relationship exists between treatment adherence and physicians' accommodation of patient preferences. The authors conceptualize preferences as what patients want from their healthcare, and they recommend that these preferences, when germane to the problem at hand, be honored in the spirit of providing high-quality and ethical care, and that the physical healthcare encounter be studied from the perspective of the patient: the person who will ultimately be deciding on whether or not to follow through with treatment decisions.

\section{Research Background and Hypotheses}

Prior to the 1990s, most healthcare decisions were made by the doctors in keeping with the paternalistic model (Sandman \& Munthe, 2010). Since the 1990s, literature has begun to address healthcare decision-making for the general population, and even more recently, for the SMI population. The literature about persons with SMI making physical healthcare decisions is still immature, and most of the studies to date look specifically at mental healthcare treatment decisions, not physical healthcare decisions. 


\section{Models of Decision-Making}

According to current literature, there are three presiding forms of treatment decisionmaking. The first is paternalistic decision-making - where the practitioner makes the decision and the patient consents to that decision, the second is shared decision-making - where the patient is provided with detailed information regarding the illness and treatment options, and the practitioner and patient come to an agreement together, and, lastly, informed decision-making where the patient has the information and the patient makes the decision completely separated from direct influence of the practitioner (Puschner et al., 2010).

\section{Study Purpose}

The primary goal of this study is to better understand the decision-making autonomy preferences of persons with SMI, and how those preferences affect treatment adherence, specifically, their physical healthcare medication. This study includes two hypotheses. First, it was hypothesized that patients who were younger, female, had less severe mental and physical health problems, had been attending the clinic longer, and had higher levels of perceived social support would prefer a higher level of desired autonomy in making health care decision. Second, when controlling for characteristic variables (listed above), it was predicted that the higher the preferred autonomy for physical healthcare decision-making and perceived autonomy support from the physician, the more adherent the person will be to their physical health medication.

\section{Methods}

\section{Study Setting}

This study was conducted at an integrated primary care clinic located onsite at a Midwestern Community Mental Health Center (CMHC). The clinic was staffed by one primary care physician, one registered nurse, and one licensed practical nurse. The clinic was started through a service grant provided by the Substance Abuse and Mental Health Services Administration (SAMHSA), and is among several others similarly funded programs around the country.

\section{Study Procedures}

All consumers in this study were adults (age 18 years and older) with SMI who were either new or returning patients to the integrated clinic. Participants were approached at the integrated care clinic waiting area after they finished an appointment with their physician. They received a brief explanation of the study, and were asked if they were interested in participating. If they agreed, the informed consent process took place. Upon consent, Time 1 measures were administered by one of the research staff. At Time 2 (three months from Time 1), participants were called by one of the research staff and asked if they would be willing to complete the brief, follow-up questions. Multiple attempts were made to reach the participant within a one-month window following the three-month mark. If they could not be reached during that time, or if their phone was disconnected, a note was made in a log and no more attempts were made. The calls were scripted and the script was followed closely.

Approval for this study was granted by the University Institutional Review Board.

\section{Measures}

A list of variables and measures can be found in Table 1. 


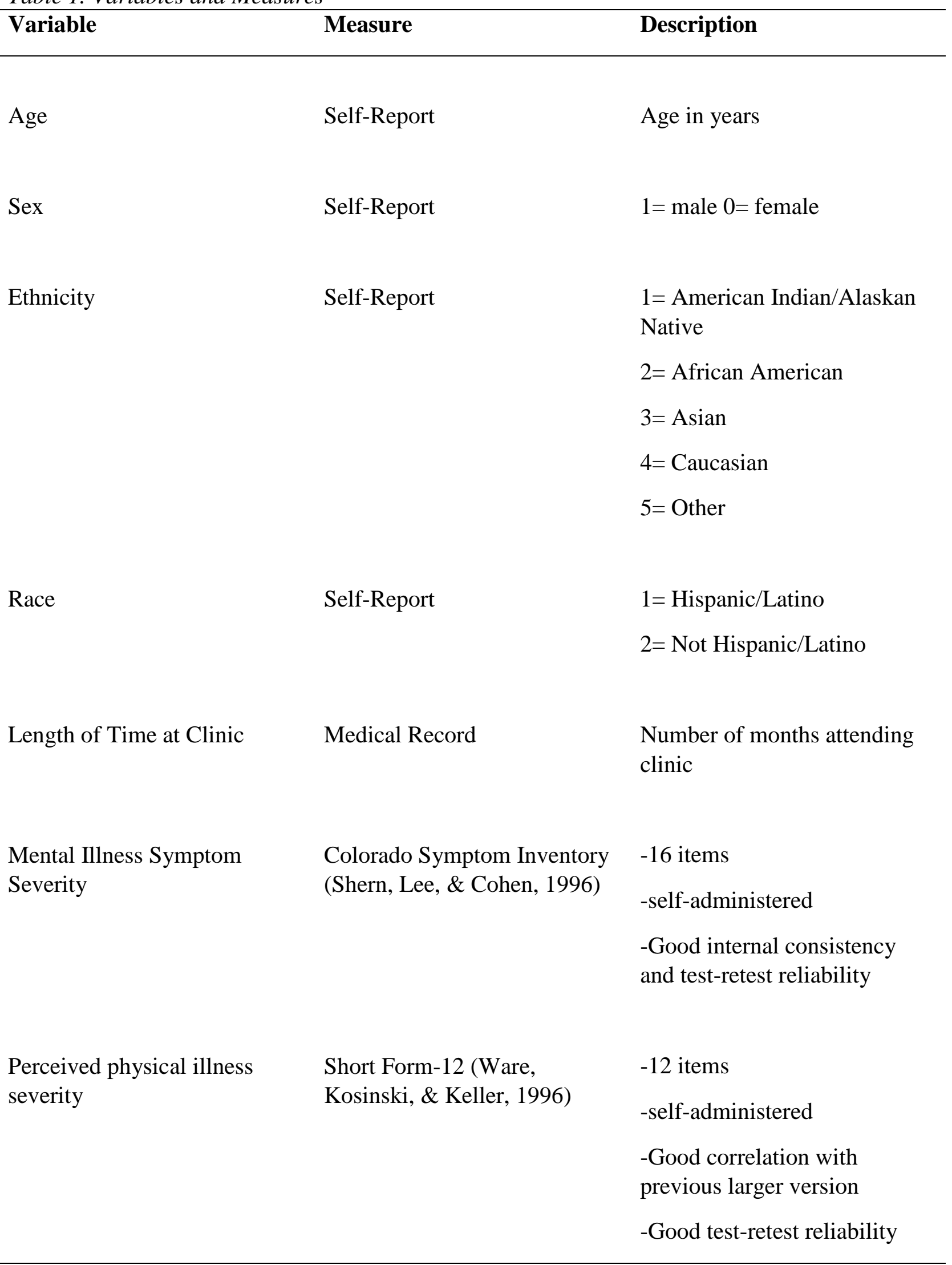




\begin{tabular}{|c|c|c|}
\hline Perceived social support & $\begin{array}{l}\text { Interpersonal Support } \\
\text { Evaluation List (ISEL) }\end{array}$ & $\begin{array}{l}\text {-30 items } \\
\text {-self-administered } \\
\text {-Good test-retest reliability } \\
\text { and internal consistency }\end{array}$ \\
\hline $\begin{array}{l}\text { Who is providing social } \\
\text { support? }\end{array}$ & $\begin{array}{l}\text { Single Question } \\
\text { Researcher Developed }\end{array}$ & -self-administered \\
\hline Autonomy Preferences & $\begin{array}{l}\text { The Autonomy Preference } \\
\text { Index, Decision-Making Scale } \\
\text { (Ende, Kazis, Ash, \& } \\
\text { Moskowitz, 1989) }\end{array}$ & $\begin{array}{l}\text {-15 total questions } \\
\text { - Six general questions } \\
\text {-Nine vignette questions, three } \\
\text { for each of three vignettes } \\
\text {-self-administered } \\
\text {-good reliability }\end{array}$ \\
\hline Perceived Autonomy Support & $\begin{array}{l}\text { The Health Climate } \\
\text { Questionnaire (Williams, } \\
\text { Grow, Freedman, Ryan, \& } \\
\text { Deci, 1996) }\end{array}$ & $\begin{array}{l}-6 \text { questions } \\
\text {-self-administered } \\
\text {-good internal consistency }\end{array}$ \\
\hline Medication Adherence & $\begin{array}{l}\text { Morisky Medication } \\
\text { Adherence Scale (Morisky, } \\
\text { Green, \& Levine, 1986) }\end{array}$ & $\begin{array}{l}\text {-4 questions } \\
\text {-self-administered } \\
\text {-Good internal consistency } \\
\text { and sensitivity }\end{array}$ \\
\hline $\begin{array}{l}\text { Barriers and Facilitators to } \\
\text { Treatment Adherence }\end{array}$ & $\begin{array}{l}\text { Open ended question at } 3 \\
\text { months }\end{array}$ & $\begin{array}{l}\text {-interviewer-administered } \\
\text {-Participants will be asked } \\
\text { what, if any, barriers and } \\
\text { facilitators they experience } \\
\text { regarding treatment adherence }\end{array}$ \\
\hline
\end{tabular}




\section{Data Analysis}

Descriptive statistics were used to highlight study participants’ background.

Multiple linear regression was used to analyze the first hypothesis. The dependent variable was decision-making autonomy preferences for physical healthcare. The predictor variables were age, sex, months attending the clinic, severity of psychiatric symptoms, perceived severity of physical illness, and appraisal of social support.

Hierarchical multiple regression (HMR) was used to analyze the second hypothesis (J. Cohen, Cohen, West, \& Aiken, 2003). The predictors used in the first hypothesis were entered as control variables (first block), and then the second block, which contained the autonomy preferences and perception of autonomy support from physician, was entered, in order to identify how much variance in medication adherence is uniquely contributed by the second block. This is done by observing the change in the variance $\left(\mathrm{r}^{2}\right)$ between the two models.

\section{Results}

\section{Background of Study Participants}

Participants for this study were 95 adults with severe mental illness attending a primary care clinic (integrated into a community mental health center) for their physical healthcare needs. As seen in Table 2, participants were mostly Caucasian (90.5\%) and males were slightly more represented (51.6\%). The average age of participants was 46.2 years. Forty-two percent of the sample had a schizophrenia spectrum diagnosis as their primary mental health issue, with $22.1 \%$ having a primary diagnosis as bipolar disorder and 20\% having major depression. For physical health diagnoses, a third 32.6\% of the sample had diabetes, $29.9 \%$ had obesity, and $26.3 \%$ had lung diseases (e.g. COPD, asthma). Average length of time participants had been attending the clinic was 7.2 months.

Table 2.

Study Sample Background Characteristics (N=95)

\begin{tabular}{llll}
\hline \multicolumn{1}{c}{ Demographic } & Frequency (\%) & Mean (SD) & Range \\
\hline Sex & $49(51.6 \%)$ & & \\
Female & $46(48.4 \%)$ & & \\
Age & & $46.2(12.4)$ & $22-82$ \\
Ethnicity & $1(1.1 \%)$ & & \\
American Indian/Alaskan & $4(4.2 \%)$ & & \\
Native & & & \\
African American & $86(90.5 \%)$ & \\
Caucasian & & \\
\hline
\end{tabular}




\begin{tabular}{lc}
\hline Other & $4(4.2 \%)$ \\
Race & \\
Hispanic & $4(4.2 \%)$ \\
Not Hispanic & $91(95.8 \%)$ \\
Primary Mental Health & \\
Diagnosis & \\
Schizophrenia & $40(42.1 \%)$ \\
Bipolar & $21(22.1 \%)$ \\
Depression & $19(20.0 \%)$ \\
Other & $15(15.8 \%)$ \\
Primary Physical Health & \\
Diagnosis & \\
Obesity & $17(17.9 \%)$ \\
Lung Diseases & $16(16.8 \%)$ \\
Hypertension & $13(13.7 \%)$ \\
Diabetes & $10(10.5 \%)$ \\
Other * & $39(41.0 \%)$
\end{tabular}

Months Attending Clinic

* Other diagnoses were varied and did not accumulate into major categories of conditions.

\section{Correlations}

Table 3 displays the correlations between study variables. The dependent variable for the first hypothesis, autonomy preferences for physical healthcare decision-making was significantly correlated with gender and autonomy support from physician: reporting more desired autonomy was associated with being male $(r=.34, p<.001)$ and perceiving lower levels of support from their physician $(r=-.21, p<.05)$. Correlation with appraisal of social support approached significance $(r=-.19, p=.06$ ). The dependent variable for the second hypothesis, medication adherence at Time 2, had several significant correlations. Patients who reported higher medication adherence at Time 2 were older $(r=.31, p<.05)$, perceived more autonomy support from their physician $(r=.30, p<.05)$, and reported higher adherence at Time $1(r=.62, p<.01)$. Alternatively, participants who reported lower adherence at Time 2 desired more autonomy in their decision-making $(r=-.31, p<.05)$ and had more severe mental health symptoms $(r=-.46$, $p<.01)$. 
Table 3.

Correlations between variables $(N=95)$

\begin{tabular}{|c|c|c|c|c|c|c|c|c|c|c|c|c|}
\hline & $\mathbf{1}$ & 2 & 3 & 4 & 5 & 6 & 7 & 8 & 9 & 10 & 11 & 12 \\
\hline $\begin{array}{l}\text { 1) Autonomy } \\
\text { Preference }\end{array}$ & 1.00 & $.34 * *$ & -.09 & .06 & $-.21 *$ & -.19 & .03 & -.05 & -.03 & -.17 & $-.31^{*}$ & -.06 \\
\hline 3) Age & & & 1.00 & $-.23 *$ & .04 & -.07 & $-.20 *$ & -.13 & -.16 & .16 & $.31 *$ & .12 \\
\hline $\begin{array}{l}\text { 4) Physical Health } \\
\text { Severity }\end{array}$ & & & & 1.00 & $.21 *$ & .05 & $.27^{*}$ & .18 & -.14 & -.11 & .20 & -.09 \\
\hline 5) Autonomy Support & & & & & 1.00 & $.22 *$ & .11 & $.25^{*}$ & -.19 & $.20^{*}$ & $.30 *$ & .16 \\
\hline $\begin{array}{l}\text { 6) Social Support } \\
\text { Appraisal }\end{array}$ & & & & & & 1.00 & $.65^{* *}$ & $.66^{* *}$ & $-.35 *$ & $.26^{*}$ & .11 & .18 \\
\hline $\begin{array}{l}\text { 7) Social Support } \\
\text { Assistance }\end{array}$ & & & & & & & 1.00 & $.72 * *$ & $-.29 * *$ & .09 & .15 & .19 \\
\hline $\begin{array}{l}\text { 8) Social Support } \\
\text { Belonging }\end{array}$ & & & & & & & & 1.00 & $-.35 * *$ & $.21 *$ & .18 & $.29 * *$ \\
\hline $\begin{array}{l}\text { 9) Mental Health } \\
\text { Symptom }\end{array}$ & & & & & & & & & 1.00 & $-.21 *$ & $-.46 * *$ & $-.21 *$ \\
\hline $\begin{array}{l}\text { 10) Med Adherence } \\
\text { Time } 1\end{array}$ & & & & & & & & & & 1.00 & $.62 * *$ & .06 \\
\hline $\begin{array}{l}\text { 11) Med Adherence } \\
\text { Time } 2\end{array}$ & & & & & & & & & & & 1.00 & .17 \\
\hline 12) Months at Clinic & & & & & & & & & & & & 1.00 \\
\hline
\end{tabular}

${ }^{1}$ Sex ( $0=$ female, $1=$ male); ${ }^{*} p<.05 ; * * p<.01$. 


\section{Model: Hypothesis 1}

As seen in Table 4, the six predictors accounted for $17 \%\left(R^{2}=.17, F(6,88)=2.99, \mathrm{p}<.01\right)$ of the variance in the dependent variable of autonomy preferences, however, only two were significant: appraisal of social support $(\beta=-.24, \mathrm{p}<.05)$ and $\operatorname{sex}(\beta=.33, \mathrm{p}<.01)$. This indicates that the more someone perceived that they had someone to talk to about their problems (appraisal of support), the less they desired autonomy in their physical health decision-making. Additionally, males desired more autonomy in physical healthcare decision-making than females. These results do not support the hypothesis that stated women and people with higher levels of perceived social support would desire more autonomy in their physical health decisionmaking. Other predictors such as age and severity of physical and mental health symptoms did not significantly contribute to the model.

Table 4.

Summary of Regression Analysis for Variables Predicting Physical Health Decision-Making Autonomy Preferences $(N=95)$

\begin{tabular}{lccc}
\multicolumn{1}{c}{ Variable } & $B$ & $S E B$ & $\beta$ \\
\hline Age & -.05 & .05 & -.11 \\
Sex (Male) & 4.14 & 1.25 & $.33^{* *}$ \\
$\begin{array}{l}\text { Social support- } \\
\text { Appraisal }\end{array}$ & -.21 & .09 & $-.24^{*}$ \\
$\begin{array}{l}\text { Mental health } \\
\text { symptoms }\end{array}$ & -.07 & .06 & -.14 \\
$\begin{array}{l}\text { Physical Health } \\
\text { Severity }\end{array}$ & .00 & .05 & .01 \\
$\begin{array}{l}\text { Months Attending } \\
\text { Clinic } \\
\boldsymbol{R}^{2}\end{array}$ & .00 & .09 & .00 \\
\hline $\begin{array}{l}* \\
p<.05 ; * * p<.01 .\end{array}$ & & &
\end{tabular}

\section{Model: Hypothesis 2.}

Table 5 displays the statistics of the HMR. The first model was significant, $F(7,49)$ $=8.74, p<.001$, and explained $55.5 \%$ of the variance. When the predictors of support for decision-making autonomy and desired autonomy preferences were added, the model was significant $F(9,47)=6.77, p<.001$ and explained $56.4 \%$ of variance. However, adding the two predictors explained only additional .09\% of variance and the increase was not significant $F$ (2, $47)=.51, p=.61$. In the first model, the strongest predictor was medication adherence at Time 1 $(\beta=.51, p<.001)$, then mental illness severity $(\beta=-.33, p<.01)$, and physical health severity $(\beta=.21, p<.05)$. When the variables of physician's autonomy support and autonomy preference were entered, significant predictors were also medication adherence at Time $1(\beta=.49, p<.001)$ and mental illness severity $(\beta=-.35, p<.01)$, but physical health severity was no longer 
significant. Therefore, when the first block of predictors was held constant, those who had high medication adherence at Time 1 and had less severe mental health symptoms reported higher adherence at Time 2 .

Table 5.

Summary of Hierarchical Multiple Regression Analysis for Predictor Variables of Physical Health Decision-Making Autonomy Preferences $(N=56)$

\begin{tabular}{|c|c|c|c|c|c|c|}
\hline \multirow[b]{2}{*}{ Variable } & \multicolumn{3}{|c|}{ Model 1} & \multicolumn{3}{|c|}{ Model 2} \\
\hline & $B$ & $S E B$ & $\beta$ & $B$ & SE B & $\beta$ \\
\hline Age & .01 & .01 & .16 & .01 & .01 & .14 \\
\hline Sex & -.03 & .22 & -.01 & .06 & .24 & .03 \\
\hline Social support: Appraisal & -.02 & .02 & -.14 & -.03 & .02 & -.18 \\
\hline Mental illness severity & -.03 & .01 & $-.33 * *$ & -.03 & .01 & $-.35 * *$ \\
\hline Physical health severity & .02 & .01 & $.21 *$ & .02 & .01 & .20 \\
\hline Months at Clinic & .01 & .02 & .05 & .01 & .02 & .05 \\
\hline $\begin{array}{l}\text { Time } 1 \text { Medication } \\
\text { Adherence }\end{array}$ & .46 & .01 & $.51^{* * *}$ & .44 & .01 & $.49 * * *$ \\
\hline $\begin{array}{l}\text { Physician Autonomy } \\
\text { Support }\end{array}$ & & & & .00 & .01 & .04 \\
\hline Autonomy Preference & & & & -.02 & .02 & -.01 \\
\hline$R^{2}$ & & & .56 & & & .56 \\
\hline
\end{tabular}

${ }^{*} p<.05 .{ }^{* *} p<.01 .{ }^{* * *} p<001$.

\section{Utility for Social Work Practice}

Social work practitioners in mental health and medical settings could benefit from the findings of this study, as they often find themselves facilitating access to medical care with people with SMI (Rees, Huby, McDade, \& McKechnie, 2004). This study suggests that people may have unique decision-making autonomy preferences in physical healthcare, given their sex and social support, and previous literature indicates that honoring autonomy preferences could improve treatment adherence. Therefore, mental and physical healthcare social workers could positively impact health outcomes given more effort to uncover these preferences. Social workers should actively engage their mental health clients in conversations about their autonomy preferences for decision-making in both mental and physical healthcare, avoiding assumptions that their autonomy preferences in decision-making in these two settings would be the same. Such discussion could be empowering, which allow clients to voice their concerns and desires about treatment. It could also lead to a more shared decision-making approach with the physician, where both patient and doctor are invested in the decision and the outcome (Joosten et al., 2008). 


\section{References}

Bosworth, H. B., Oddone, E. Z., \& Weinberger, M. (2008). Patient Treatment Adherence: Concepts, Interventions and Measurement. Mahwah, NJ: Lawrence Earlbaum Associates, Inc.

Ende, J., Kazis, L., Ash, A., \& Moskowitz, M. (1989). Measuring patients’ desire for autonomy. Journal of General Internal Medicine, 4(1), 23-30. doi: 10.1007/bf02596485

Lutterman, T., Ganju, V., Schacht, L., Monihan, K. et al. . (2003). Sixteen State Study on Mental Health Performance Measures. Rockville, MD.

McGrath, J., Saha, S., Chant, D., \& Welham, J. (2008). Schizophrenia: A Concise Overview of Incidence, Prevalence, and Mortality. Epidemiologic Reviews, 30(1), 67-76. doi: 10.1093/epirev/mxn001

Mitchell, A. J., Vancampfort, D., Sweers, K., van Winkel, R., Yu, W., \& De Hert, M. (2013). Prevalence of Metabolic Syndrome and Metabolic Abnormalities in Schizophrenia and Related Disorders-A Systematic Review and Meta-Analysis. Schizophrenia Bulletin, 39(2), 306-318. doi: 10.1093/schbul/sbr148

Morisky, D. E., Green, L. W., \& Levine, D. M. (1986). Concurrent and predictive validity of a self-reported measure of medication adherence. Med Care, 24(1), 67-74.

NIMH (Producer). (2001, April 20, 2011). The numbers count: Mental disorders in America. Retrieved from http://www.nimh.nih.gov/statistics/index.shtml

Puschner, B., Steffen, S., Slade, M., Kaliniecka, H., Maj, M., Fiorillo, A., . . B Becker, T. (2010). Clinical Decision Making and Outcome in Routine Care for People with Severe Mental Illness (CEDAR): Study protocol. BMC Psychiatry, 10(1), 90.

Rees, G., Huby, G., McDade, L., \& McKechnie, L. (2004). Joint working in community mental health teams: implementation of an integrated care pathway. Health \& Social Care in the Community, 12(6), 527-536. doi: 10.1111/j.1365-2524.2004.00523.x

Sandman, L., \& Munthe, C. (2010). Shared Decision Making, Paternalism and Patient Choice. Health Care Analysis, 18(1), 60-84. doi: 10.1007/s10728-008-0108-6

Shern, D., Lee, B., \& Cohen, A. (1996). The Colorado Symptom Inventory: A self-report measure for psychiatric symptoms. Louis de la Parte Mental Health Institute. Tampa, FL.

Street, R. L., Elwyn, G., \& Epstein, R. M. (2012). Patient preferences and healthcare outcomes: an ecological perspective. Expert Review of Pharmacoeconomics \& Outcomes Research, 12(2), 167-180. doi: 10.1586/erp.12.3

Ware, J. E. J., Kosinski, M., \& Keller, S. D. (1996). A 12-Item Short-Form Health Survey: Construction of Scales and Preliminary Tests of Reliability and Validity. Medical Care, 34(3), 220-233.

Williams, G. C., Grow, V. M., Freedman, Z. R., Ryan, R. M., \& Deci, E. L. (1996). Motivational predictors of weight loss and weight loss maintenance. Journal of Personality and Social Psychology, 70(1), 115-126. 